\section{Yttrium-90-labeled anti-CD45 antibody followed by a reduced-intensity hematopoietic cell transplantation for patients with relapsed/refractory leukemia or myelodysplasia}

\author{
Phuong Vo, ${ }^{1,2}$ Ted A. Gooley, ${ }^{1,2}$ Joseph G. Rajendran, ${ }^{3}$ Darrell R. Fisher, ${ }^{4}$ Johnnie \\ J. Orozco,,$^{1,2}$ Damian J. Green, ${ }^{1,2}$ Ajay K. Gopal, ${ }^{1,2}$ Robyn Haaf, ${ }^{1}$ Margaret \\ Nartea, ${ }^{1}$ Rainer Storb, ${ }^{1,2}$ Frederick R. Appelbaum, ${ }^{1,2}$ Oliver W. Press, ${ }^{1,2, \dagger}$ John M. \\ Pagel $^{5^{\circ}}$ and Brenda M. Sandmaier ${ }^{1,2}$ \\ ${ }^{1}$ Division of Clinical Research, Fred Hutchinson Cancer Research Center, Seattle; \\ ${ }^{2}$ Department of Medicine, University of Washington, Seattle; ${ }^{3}$ Department of Radiology, \\ University of Washington, Seattle; ${ }^{4}$ Versant Medical Physics and Radiation Safety, \\ Richland and ${ }^{5}$ Swedish Cancer Institute, Seattle, WA, USA \\ ${ }^{\circ}$ Current address: Swedish Medical Center, Seattle, WA, USA \\ ${ }^{\dagger}$ Posthumous.
}

\section{ABSTRACT}

( utcomes of patients with persistent high-risk leukemia or myelodysplasia prior to allogeneic hematopoietic cell transplantation are dismal. We therefore conducted a phase I trial evaluating the use of CD45-targeted radiotherapy preceding hematopoietic cell transplantation with the goal of improving outcomes for this high-risk scenario. Fifteen patients, median age 62 (range 37-76) years, were treated: ten with advanced acute myeloid leukemia, five with high-risk myelodysplastic syndrome. All patients had evidence of disease prior to treatment including nine with marrow blast counts ranging from $7-84 \%$ and six with minimal residual disease. Patients received escalating doses of yttrium-90-labeled anti-CD45 antibody followed by fludarabine and 2 Gy total body irradiation prior to human leukocyte antigen-matched, related or unrelated hematopoietic cell transplantation. Although a maximum dose of $30 \mathrm{~Gy}$ was delivered to the liver, no dose-limiting toxicity was observed. Therefore, the maximum-tolerated dose could not be estimated. Treatment led to complete remission in 13 patients $(87 \%)$. All patients engrafted by day 28 . Six patients relapsed, median of 59 (range 6-351) days, after transplantation. The 1-year estimate of relapse was $41 \%$. Eight patients (53\%) are surviving with median follow up of 1.8 (range $0.9-5.9$ ) years. Estimated overall survival at one and two years was $66 \%$ and $46 \%$, respectively, with progression-free survival estimated to be $46 \%$ at each time point. In conclusion, the combination of ${ }^{90} Y$-DOTABC8 with an allogeneic hematopoietic cell transplantation regimen was feasible and tolerable. This approach appears promising in this high-risk leukemia/myelodysplasia patient population with active disease. (Trial registered at clinicaltrials.gov identifier: NCT01300572.)

\section{Introduction}

Allogeneic hematopoietic cell transplantation (HCT) is a commonly used therapy for patients with refractory/relapsed acute leukemia and myelodysplastic syndrome (MDS) with unfavorable genetics. Although HCT is the most effective treatment for these patients, the procedure is associated with significant toxicities, especially for elderly patients. Reduced-intensity preparative regimens have been developed as an alternative approach for older patients and those with comorbidities that might prevent them from undergoing a myeloablative HCT. Standard reduced-intensity conditioning regimens, however, have been commonly associated with higher relapse rates
Haematologica 2020

Volume 105(6):1731-1737

\section{Correspondence:}

BRENDA M. SANDMAIER

bsandmai@fredhutch.org

Received: June 13, 2019.

Accepted: October 3, 2019.

Pre-published: October 3, 2019.

doi:10.3324/haematol.2019.229492

Check the online version for the most updated information on this article, online supplements, and information on authorship \& disclosures: www.haematologica.org/content/105/6/1731

\section{(C)2020 Ferrata Storti Foundation}

Material published in Haematologica is covered by copyright All rights are reserved to the Ferrata Storti Foundation. Use of published material is allowed under the following terms and conditions:

https://creativecommons.org/licenses/by-nc/4.0/legalcode. Copies of published material are allowed for personal or internal use. Sharing published material for non-commercial purposes is subject to the following conditions:

https://creativecommons.org/licenses/by-nc/4.0/legalcode, sect. 3. Reproducing and sharing published material for commercial purposes is not allowed without permission in writing from the publisher. 
in patients with an advanced burden of active leukemia at the time of transplantation. ${ }^{1}$ We previously combined iodine-131-labeled anti-CD45 monoclonal antibody ( ${ }^{131} \mathrm{I}-$ BC8) with a reduced-intensity conditioning regimen to decrease relapse in older patients with advanced or refractory myeloid malignancies. ${ }^{2}$ While the study was not designed to examine potential efficacy, the 3-year diseasefree survival was $38 \%$ for 58 patients with active relapsed/refractory leukemia, a rate superior to historical experience where the 3-year overall and disease-free survival estimates of these patients were only $23 \%$ and $13 \%$, respectively. ${ }^{1,3}$ Furthermore, $86 \%$ of the patients had acute myeloid leukemia (AML) in active relapse or MDS with more than $5 \%$ blasts in their marrow by morphology at the time of HCT. All patients achieved a complete remission as well as 100\% donor chimerism in the CD3 and CD33 compartments by day 28. The maximum-tolerated dose (MTD) was estimated to be 24 Gy delivered by ${ }^{131}$ I-BC8 to the normal organ receiving the highest dose (liver), with renal insufficiency and cardiopulmonary toxicities being doselimiting.

We used ${ }^{131} \mathrm{I}$ as the therapeutic radionuclide in our prior clinical studies because it was readily available, there was extensive experience with its medical use, the technology for directly radiolabeling antibodies with iodine has been well established, and its gamma-ray component allowed direct determination of labeled antibody biodistribution in the patient after a tracer infusion. However, the high abundance gamma radiation component of ${ }^{131}$ I requires that patients be treated and sequestered in radiation isolation and poses a potential radiation exposure risk for staff and family, presenting a major limitation to the wide-spread exportability of this modality. As an alternative, ytrium-90 $\left.{ }^{90} \mathrm{Y}\right)$ has been explored as a pure $\beta$-emitter that has been available in high specific activity and purity. Moreover, the $\beta$ particles from ${ }^{90} Y$ have a high energy $(\operatorname{Emax}=2.28 \mathrm{MeV})$ with greater tissue penetrating range (up to $11 \mathrm{~mm}$ ) that may be more favorable for near-uniform deposition of radiation energy in tumor masses. ${ }^{4}$

In this current study, we evaluated the safety and potential efficacy of ${ }^{90}$ Y-labeled anti-CD45 antibody $\left({ }^{90}\right.$ Y-DOTABC8) followed by a standard reduced-intensity regimen with fludarabine (FLU) and 2 Gy total body irradiation (TBI) as a means of developing an improved HCT strategy for high-risk acute leukemia or MDS patients.

\section{Methods}

\section{Patient and donor selection}

Patients aged 18 years and older were eligible if they had advanced AML (beyond first remission, primary refractory, relapsed with $>5 \%$ marrow blasts by morphology, or evolved from previous myeloproliferative neoplasm or MDS), MDS with $>5 \%$ blasts in the marrow, or chronic myelomonocytic leukemia-2, and if they had an HLA-matched donor. Patients were excluded if they had evidence of major organ dysfunction, seropositivity for human immunodeficiency virus, allergies to mouse protein, or human antibody specific for mouse immunoglobulin (HAMA). All patients signed consent forms approved by the institutional review board of Fred Hutchinson Cancer Research Center. (NCI Clinical Trials Network registration: clinicaltrials.gov identifier: NCT01300572.)

\section{Treatment plan}

The patients received an infusion of $0.5 \mathrm{mg} / \mathrm{kg}$ ideal body weight of anti-CD45 antibody (DOTA-BC8) trace-labeled with 5$10 \mathrm{mCi}$ of the imaging radionuclide indium-111 $\left({ }^{111} \mathrm{In}\right)$, which provides gamma photons $(0.171$ and $0.245 \mathrm{MeV}$ ) for imaging (not provided by ${ }^{90} \mathrm{Y}$ ), to evaluate the biodistribution of the anti-CD45 antibody and calculate the radiation-absorbed doses delivered to normal organs and the whole body, as described previously. ${ }^{2}$ The subsequent therapy infusion of ${ }^{9} \mathrm{Y}-\mathrm{DOTA}-\mathrm{BC} 8$ was calculated to not exceed a maximum value dose to the critical normal organ. The therapy dose was administered on approximately day -12 of the preparative regimen. FLU $30 \mathrm{mg} / \mathrm{kg} /$ day was given intravenously (i.v.) on days -4 through -2 , followed by TBI (2 Gy) and subsequent infusion of unmanipulated, G-CSF-mobilized peripheral blood stem cells on day 0. Mycophenolate mofetil and cyclosporine was given for graft-versus-host-disease (GvHD) prophylaxis. $^{5}$

\section{Dose-adjustment schema and statistical analysis}

The primary objective of this study was to estimate the MTD of ${ }^{90} Y-D O T A-B C 8$ used in combination with FLU/2-Gy TBI. The MTD was defined as the radiation dose to the normal organ associated with a dose-limiting toxicity (DLT) rate of $25 \%$ using Bearman criteria, developed specifically for HCT patients. ${ }^{6}$ A DLT was defined as a Bearman grade III or IV regimen-related toxicity occurring up to day 100 after HCT. ${ }^{6}$ A two-stage approach described by Storer et al. was planned for dose adjustment.' In stage I, single patient cohorts were enrolled, and each successive patient received 2 Gy more radiation to the dose-limiting normal organ than the previous patient until the first DLT was observed. Dose escalation could proceed only if the patient receiving the previous dose was observed for at least 30 days after HCT; if not, the newly enrolled patient had to be treated at the same dose level as the previous patient. If a DLT was observed, stage II would be initiated at the next lower dose level, treating patients in cohorts of four patients each; this cohort size was dictated by the target DLT rate of $25 \%$

Secondary objectives included evaluation of potential efficacy in the context of a dose-finding study. Overall survival (OS) and relapse-free survival (RFS) were estimated according to the Kaplan-Meier method, and relapse and non-relapse mortality (NRM) were summarized using cumulative incidence estimates. NRM was considered a competing risk for relapse, and relapse was treated as a competing risk for NRM.

\section{Results}

\section{Patients' characteristics}

Sixteen patients with high-risk leukemia/MDS were enrolled to the study. One patient was withdrawn from the study due to HAMA seroconversion after receiving the ${ }^{111}$ In-DOTA-BC8 test dose. Thus, fifteen patients, median age 62 years (range 37-76 years) years, were treated: ten patients had advanced AML and five had high-risk MDS. At the time of HCT, nine patients had refractory active diseases (pre-HCT marrow blast range $7-83.9 \%$ ), while six had minimal residual disease documented by flow cytometry and cytogenetics (Table 1). Among the ten AML patients, three patients with de novo AML had relapsed disease and were refractory to a median of four lines of previous chemo-induction (range 3-6). Seven patients with secondary AML had received a median of three (range 1-6) induction chemotherapies prior to the HCT. Three of the 15 patients had failed previous alloHCT. According to Southwest Oncology Group criteria, ${ }^{8}$ eight patients had high-risk/unfavorable cytogenetic 
abnormalities, and the remaining seven patients had intermediate-risk cytogenetic abnormalities. The median HCT-comorbidity index of the 15 treated patients was three (range 0-7).

Three patients had HLA-matched related donors, and 12 had unrelated donors, of which ten were 10/10 HLAmatched, one was HLA-A antigen mismatched, and one had an allele mismatch at HLA-DO.

The patients received an average of $78.6 \mathrm{mCi}$ of ${ }^{90} \mathrm{Y}$ (range 22.8-151.2 $\mathrm{mCi}$ ), with average delivered doses of 10.5 Gy to marrow, 70 Gy to spleen, and 17.9 Gy to liver through complete radionuclide decay. Although a maximum dose of 30 Gy was delivered to the liver, no DLT was observed; therefore, the MTD could not be estimated. Despite the lack of any DLT observed among the 15 patients treated, the BC8 antibody was not labeled with higher amounts of ${ }^{\circ 0} \mathrm{Y}$ that would deliver more than $30 \mathrm{~Gy}$ to any critical normal organ because of concerns of potential damage to the antibody avidity and function.

\section{Dosimetry, biodistribution and engraftment}

Since the biokinetics of ${ }^{90}$ Y-labeled anti-CD45 antibody vary substantially from one patient to another, treatment planning based on individualized patient dosimetry enables a therapy that maximizes therapeutic efficacy without exceeding normal organ toxicity. The mean absorbed dose per unit administered activity (cGy/mCi \pm standard deviation) for the 15 treated patients was: $15.25 \pm 7.05$ to the bone marrow, $24.99 \pm 6.76$ to liver, $106.1 \pm 33.19$ to spleen, $8.14 \pm 4.79$ to kidney, $6.69 \pm 19.5$ to lung, and $2.16 \pm 0.55$ to the total body (Figure 1 and Online Supplementary Table S1). The calculated absorbed doses of ${ }^{90} Y$ to liver, marrow and spleen are summarized in Table 2.

Median CD34 $4^{+}$cell dose of the 15 transplanted patients was 9.03 (range 2.14-15.86) x10 $/ \mathrm{kg}$. Median time to neutrophil engraftment [absolute neutrophil count (ANC) $>0.5 \times 10^{9} /$ L for 3 consecutive days] was 15 (range 12-26) days. Median time to platelet engraftment (platelets $>20$ $\mathrm{x} 10^{\circ} / \mathrm{L}$ for 7 consecutive days without transfusion support) was 16.5 (range 12-74) days. All patients engrafted with median donor-derived CD3 chimerisms of $99 \%$ and
CD33 chimerisms of $100 \%$ by day 28 , with $100 \%$ median donor-derived CD3 and CD33 chimerisms for both by day 84 after HCT.

Table 1. Characteristics of 15 patients who received a therapeutic dose of ${ }^{\circ 0}$-DOTA-BC8.

\begin{tabular}{|c|c|}
\hline Median age, [years (range)] & $62(37-76)$ \\
\hline $\begin{array}{l}\text { Sex } \\
\quad \text { Male } \\
\text { Female }\end{array}$ & $\begin{array}{l}8 \\
7\end{array}$ \\
\hline $\begin{array}{l}\text { Diagnosis at HCT } \\
\text { AML, total n } \\
\text { Secondary AML, total n } \\
\text { Refractory disease } \\
\text { In CR1 with (+) MRD } \\
\text { In CR2 with (+) MRD } \\
\text { Rel } 1 \\
\text { Primary AML, total n } \\
\text { Rel } 1 \\
\text { Rel } 2 \\
\text { MDS-RAEB, total n } \\
\text { Refractory disease } \\
\text { In CR1 with (+) MRD } \\
\text { Untreated CMML }\end{array}$ & $\begin{array}{l}10 \\
7 \\
1 \\
4 \\
1 \\
1 \\
3 \\
1 \\
2 \\
4 \\
3 \\
1 \\
1\end{array}$ \\
\hline $\begin{array}{l}\text { History of previous allo-HCT } \\
\text { Cytogenetic risk } \\
\text { Intermediate } \\
\text { High/unfavorable }\end{array}$ & $\begin{array}{l}3 \\
7 \\
8\end{array}$ \\
\hline $\begin{array}{l}\text { Donor status } \\
\text { Related } \\
\text { Unrelated }\end{array}$ & $\begin{array}{c}3 \\
12\end{array}$ \\
\hline $\begin{array}{l}\text { Median n. pre-HCT induction che } \\
\text { AML } \\
\text { Secondary } \\
\text { Primary } \\
\text { MDS-RAEB } \\
\text { CMML }\end{array}$ & $\begin{array}{l}3(1-6) \\
4(3-6) \\
1(1-2) \\
0\end{array}$ \\
\hline
\end{tabular}

HCT: allogeneic hematopoietic cell transplantation; AML: acute myeloid leukemia; CR1: first complete remission; CR2: second CR; MRD: measurable residual disease; $C R$ : complete remission; Rel: relapse; MDS-RAEB: myelodysplastic syndrome-refractory anemia with excess blasts; CMML: chronic myelomonocytic leukemia; n: number.

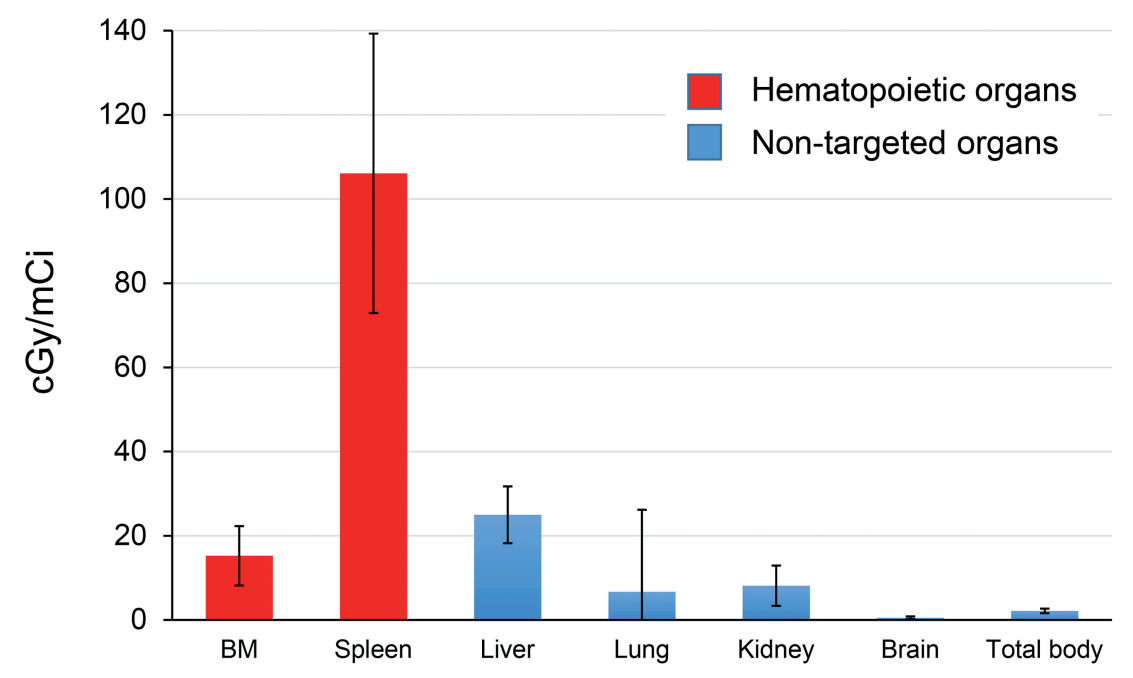

Figure 1. Estimated radiation absorbed doses per millicurie of ${ }^{90} \mathrm{Y}$ administered for 15 patients who received a therapeutic dose of ${ }^{90}$ Y-DOTA-BC8. 
Table 2. ${ }^{90} \mathrm{Y}$ activity administered and total radiation absorbed doses* to dose-limiting organ (liver), marrow, and spleen.

\begin{tabular}{|c|c|c|c|c|c|}
\hline $\begin{array}{l}\text { Dose level (targeted } \\
\text { dose }^{\dagger} \mathrm{Gy} \text { ) }\end{array}$ & Patient number & $\begin{array}{l}\text { Therapy dose delivered, } \\
\mathrm{mCi}(\mathrm{MBq})\end{array}$ & $\begin{array}{l}\text { Dose to liver, } \\
\text { cGy }\end{array}$ & $\begin{array}{l}\text { Dose to marrow, } \\
\text { cGy }\end{array}$ & $\begin{array}{c}\text { Dose to spleen, } \\
\text { cGy }\end{array}$ \\
\hline $1(6)$ & 1 & $22.80(843.60)$ & 570 & 247.38 & 2508 \\
\hline $2(8)$ & 2 & $27.06(1001.22)$ & 838.86 & 534.43 & 2814.24 \\
\hline $3(10)$ & 3 & $30.30(1121.10)$ & 951.42 & 601.45 & 3120.9 \\
\hline $4(12)$ & 4 & $45.50(1683.50)$ & 978.25 & 51.87 & 3676.4 \\
\hline $5(14)$ & 5 & $38.40(1420.80)$ & 1413.12 & 1019.52 & 7219.2 \\
\hline $6(16)$ & 6 & $53.70(1986.90)$ & 1594.89 & 622.92 & $0^{\ddagger}$ \\
\hline $6(16)$ & 7 & $65.10(2408.70)$ & 1660.05 & 823.51 & 6379.8 \\
\hline $7(18)$ & 8 & $128.30(4747.10)$ & 1783.37 & 1321.49 & 6568.96 \\
\hline $8(20)$ & 9 & $70.80(2619.60)$ & 1932.84 & 730.65 & 7929.6 \\
\hline $9(22)$ & 10 & $141.20(5224.40)$ & 2230.96 & 3897.12 & 14402.4 \\
\hline $10(24)$ & 11 & $112.40(4158.80)$ & 2326.68 & 1354.42 & 9891.2 \\
\hline $10(24)$ & 12 & $151.20(5594.40)$ & 2358.72 & 1670.76 & 8542.8 \\
\hline $11(26)$ & 13 & $81.50(3015.50)$ & 2583.55 & 1662.6 & $0^{\ddagger}$ \\
\hline $12(28)$ & 14 & $104.00(3848.00)$ & 2797.6 & 1632.8 & 12376 \\
\hline $13(30)$ & 15 & $104.70(3873.90)$ & 2858.31 & 961.14 & 13506.3 \\
\hline
\end{tabular}

*Among patients who received a therapeutic dose of ${ }^{\circ} \mathrm{Y}$-DOTA-BC8. $\dagger$ Targeted radiation dose to normal organ receiving highest dose (liver). $\ddagger$ Patients with splenectomy.

\section{Toxicities and graft-versus-host disease}

Despite premedication, grade 1-2 antibody-related infusion reactions (e.g. fever and chills) were observed in 6 of 15 patients; however, the reactions resolved by the end of each infusion. Notably, no grade 4 Common Toxicity Criteria Adverse Event (CTCAE) was observed. Ten (67\%) patients experienced grade 3 non-hematologic events (Table 3). Hepatic veno-occlusive disease was not observed, despite delivering an average of 17.9 Gy to the liver. Ten patients $(67 \%)$ developed grade II-IV acute GvHD (grade II: $n=8 ;$ III: $n=1 ;$ IV: $n=1$ ) (Table 4). Five patients $(33 \%$ ) developed chronic GvHD, most commonly involving skin and mouth.

\section{Overall and relapse-free survival, non-relapse mortality, and relapse}

Treatment led to complete remission in 13 patients (87\%) based on a day-28 BM evaluation, whereas two patients had persistent disease documented by peripheral blood flow cytometry assessment on day 6 and day 20 after HCT (Table 5). Of note, the two patients with persistent disease had $83.9 \%$ and $70 \%$ marrow blasts before transplant, respectively. One of these two patients had also failed a previous allogeneic HCT. Among the 15 patients who received a therapy dose infusion of ${ }^{\circ} \mathrm{Y}$-DOTA-BC8, eight patients are still alive with a median follow up of 1.8 (range 0.9-5.9) years. Estimated $O S$ at one and two years were $66 \%$ (confidence interval, CI: $36-84$ ) and $46 \%$ (CI: 17-71), respectively, with RFS estimated to be $46 \%$ (CI: 20 68) at each of these time points. The 1-year estimate of relapse was $41 \%(16-65 \%)$. Figure 2 summarizes the probabilities of OS, RFS, and relapse among all 15 patients. Six patients relapsed, five of whom subsequently died due to progression of disease. The median time to relapse among these six patients was 59 days (range 6-351 days). One patient died from grade IV steroid-refractory GvHD in remission at day 71 , which resulted in a $6.6 \%$ day-100 NRM. One patient died also in remission from acute renal failure seven months after HCT while receiving foscarnet for cytomegalovirus reactivation.
Table 3. Grades 3 and 4 non-hematologic adverse events of the 15 patients who received a therapeutic dose of ${ }^{90} \mathrm{Y}$-DOTA-BC8.

\begin{tabular}{lcc} 
NCI CTCAE term & Grade 3 & Grade 4 \\
Febrile neutropenia & 7 & 0 \\
Infection & 2 & 0 \\
\hline Blood bilirubin increased & 2 & 0 \\
Hyperglycemia & 1 & 0 \\
\hline Rash & 4 & 0 \\
Skeletal muscular pain & 4 & 0 \\
\hline Hypoxia & 1 & 0 \\
Atrial fibrillation & 1 & 0 \\
\hline Nausea/vomiting & 3 & 0 \\
Diarrhea & 2 & 0 \\
\hline Hematoma & 1 & 0 \\
Mucositis & 1 & 0 \\
\hline Hematoma & 1 & 0 \\
Edema & 1 & 0 \\
\hline
\end{tabular}

NCI CTCAE: National Cancer Institute Common Terminology Criteria for Adverse Events, version 4.0.

\section{Discussion}

Although allogeneic HCT is an important and frequently used treatment for advanced AML and high-risk MDS, many patients have recurrent disease. ${ }^{9,10}$ In a randomized study of patients with AML in first complete remission, the relapse rate was $12 \%$ after 15.75 Gy TBI, compared with $35 \%$ after 12 Gy TBI. ${ }^{11}$ Although this study showed improved leukemia control with escalated doses of TBI, the higher doses of TBI were associated with increased NRM, resulting in no improvement in survival. The finding also confirmed that the high-dose TBI preparative regimens were at the limit of normal organ tolerance.

The results reported from studies that used reducedintensity conditioning suggest that a graft-versus-malig- 
nancy effect is most effective in patients with a low burden of malignant cells. ${ }^{1,12,13}$ In a study of 274 patients who had allogeneic HCT after non-myeloablative conditioning using FLU and 2 Gy TBI for the treatment of AML, patients in first and second complete remission had better 5 -year survival rates than patients with more advanced disease (37\% and $34 \%$ vs. $18 \%$, respectively). Most treatment failures were caused by recurrent AML. ${ }^{14}$ These data suggest that a graft-versus-leukemia effect alone may be inadequate for patients with $\mathrm{AML} / \mathrm{MDS}$ in relapse or with refractory disease, whereas additional targeted antileukemic therapy may be beneficial. Our group previously explored the safety and feasibility of ${ }^{131}$ I-BC8 antibody to deliver targeted radiation to malignant cells in the marrow and spleen, and combined this approach with the non-myeloablative conditioning regimen of $2 \mathrm{~Gy} \mathrm{TBI}$ and FLU in patients with advanced myeloid malignancies., ${ }^{2,15}$

Table 4. Acute graft-versus-host disease overall grading with organ staging of the 15 patients.

\begin{tabular}{lcccc}
\hline Grade/stage & Overall (n) & Gut (n) & Liver (n) & Skin (n) \\
I/1 & 1 & 9 & 2 & 1 \\
II/2 & 8 & 0 & 0 & 2 \\
\hline III/3 & 1 & 0 & 1 & 4 \\
IV/4 & 1 & 1 & 0 & 0 \\
\hline
\end{tabular}

While results were encouraging, one major limitation of this approach was the medium energy gamma component of ${ }^{131}$ I and 8-day physical half-life that required patients to be treated in radiation isolation due to the exposure risk for staff and family. ${ }^{90} \mathrm{Y}$ was selected as the therapeutic radionuclide for this current clinical trial because it is a pure $\beta$-emitter that is available in high specific activity and purity. Moreover, the $\beta$ particles from ${ }^{90} \mathrm{Y}$ have a high energy (Emax $=2.28 \mathrm{MeV}$ ) with greater tissue penetrating range (up to $11 \mathrm{~mm}$ ) than $\beta$ particles from ${ }^{131} \mathrm{I}$, characteristics that may be more favorable for therapy of large tumor masses. ${ }^{4}$ Finally, replacement of ${ }^{131} \mathrm{I}$ with ${ }^{90} \mathrm{Y}$ may be more feasible for studies at additional centers.

As a phase I dose-finding trial, the current study was not designed to determine the efficacy of the conditioning regimen of ${ }^{90} Y$-DOTA-BC8 combined with FLU/TBI. However, the experience reported in this dose-escalation study suggests that the delivery of supplemental doses of ${ }^{90} \mathrm{Y}-\mathrm{DOTA}-\mathrm{BC} 8$ could improve 2-year OS and RFS of very high-risk AML/MDS patients to $46 \%$ and $46 \%$, respectively, compared with patients who received HCT with the use of the FLU/TBI conditioning regimen alone..$^{1,3,14}$ Although the estimated probability of relapse at one year remains high at $41 \%$, these results are encouraging, considering that all of the patients in our study had either active AML/MDS or measurable residual disease (MRD) prior to the beginning of the conditioning regimen. Patients with detectable disease have historically dismal

Table 5. Outcomes of the 15 patients who received a therapeutic dose of ${ }^{90} \mathrm{Y}$-DOTA-BC8.

\begin{tabular}{|c|c|c|c|c|c|c|c|c|c|}
\hline Pt & $\begin{array}{l}\text { Age/ } \\
\text { Gender }\end{array}$ & $\begin{array}{c}\text { Diagnosis at } \\
\text { HCT }\end{array}$ & $\begin{array}{l}\text { Disease status } \\
\text { at transplant }\end{array}$ & $\begin{array}{l}\text { Pre-HCT BM/PB } \\
\text { blast (\%) }\end{array}$ & $\begin{array}{l}\text { Cytogenetic } \\
\text { risk* }\end{array}$ & $\begin{array}{l}\text { CR }^{\dagger} \\
\text { Achievement } \\
\text { post HCT }\end{array}$ & $\begin{array}{l}\text { Donor } \\
\text { status }\end{array}$ & $\begin{array}{l}\text { Grade } \\
\text { acute } \\
\text { GvHD }\end{array}$ & $\begin{array}{l}\text { Current status, days } \\
\text { after HCT }\end{array}$ \\
\hline 1 & $51 / \mathrm{M}$ & Relapsed secondary AML & Active disease & $83.9 / 0$ & high & No & URD & 0 & $\begin{array}{l}\text { Persistent disease; died } \\
\text { day } 23\end{array}$ \\
\hline 2 & $69 / \mathrm{M}$ & Refractory secondary AML & $\operatorname{MRD}(+)$ & $0 / 0^{\ddagger}$ & high & Yes & URD & 2 & Alive and in CR: $2137 \mathrm{~d}$ \\
\hline 3 & $74 / \mathrm{M}$ & MDS-RAEB & $\operatorname{MRD}(+)$ & $1.4 / 0$ & Int. & Yes & URD & 0 & $\begin{array}{l}\text { Died day } 218 \text { due to renal } \\
\text { failure (in CR) }\end{array}$ \\
\hline 4 & $76 / \mathrm{M}$ & MDS-RAEB & Active disease & $13.6 / 0$ & Int. & Yes & URD" & 4 & $\begin{array}{l}\text { Died day } 80 \text { due to steroid } \\
\text { refractory aGvHD (in CR) }\end{array}$ \\
\hline 5 & $52 / F$ & Refractory secondary AML & $\operatorname{MRD}(+)$ & $3.5 / 0$ & Int. & Yes & URD & 2 & Died day 694 due to relapse \\
\hline 6 & $65 / \mathrm{M}$ & Refractory secondary AML & $\operatorname{MRD}(+)$ & $0.22 / 1.1$ & Int. & Yes & URD & 2 & Alive and in CR: $1234 \mathrm{~d}$ \\
\hline 7 & $48 / F$ & Relapsed secondary AML & $\operatorname{MRD}(+)$ & $0.17 / 0$ & high & Yes, with MRD & URD & 2 & Died day 395 due to relapse \\
\hline 8 & $60 / \mathrm{M}$ & Refractory secondary AML & Active disease & $17.6 / 3.6$ & high & Yes & URD & 0 & Alive and in CR: $767 \mathrm{~d}$ \\
\hline 9 & $56 / \mathrm{F}$ & Relapse/refractory AML & Active disease & $31.6 / 0$ & Int. & Yes & URD & 2 & Alive and in CR: $727 \mathrm{~d}$ \\
\hline 10 & $37 / \mathrm{F}$ & Relapse/refractory AML & Active disease & $70.0 / 0$ & Int. & No & URD & 3 & $\begin{array}{l}\text { Persistent disease; died } \\
\text { day } 109\end{array}$ \\
\hline 11 & 71/M & MDS-RAEB & Active disease & $7.0 / 0$ & high & Yes, with MRD & $\mathrm{RD}$ & 0 & $\begin{array}{l}\text { Alive, on azacytidine, } \\
\text { achieved CR with MRD (-): } \\
583 \text { d }\end{array}$ \\
\hline 12 & $72 / \mathrm{M}$ & Secondary AML & $\operatorname{MRD}(+)$ & $2.5 / 1.5$ & high & Yes & URD & 2 & Died day 318 due to relapse \\
\hline 13 & $65 / \mathrm{F}$ & Untreated CMML & Active disease & $0.89 / 0$ & Int. & Yes & $\mathrm{RD}$ & 2 & $\begin{array}{l}\text { Alive: relapsed on day } \\
\text { 351. Currently on azacytidine } \\
\text { and now CR with MRD (-) }\end{array}$ \\
\hline 14 & $62 / F$ & MDS-RAEB & Active disease & $11.4 / 0.38$ & high & Yes & $\mathrm{RD}$ & 1 & Alive and in CR: $394 \mathrm{~d}$ \\
\hline 15 & $37 / \mathrm{F}$ & Relapse/refractory AML & Active disease & $43.0 / 4.0$ & high & Yes, with MRD & URD & 2 & $\begin{array}{l}\text { Alive and in CR with MRD (+) } \\
316 \mathrm{~d}\end{array}$ \\
\hline
\end{tabular}

BM: bone marrow; CMML: chronic myelomonocytic leukemia; CR: complete remission; F: female; Int.: intermediate; M: male; MDS-RAEB: myelodysplastic syndrome-refractory anemia with excess blast; MRD: measurable residual disease; PB: peripheral blood; RD: HLA-matched related donor; URD: unrelated donor. *According to Southwest Oncology Group criteria. 'Protocol-defined CR as bone marrow with blasts $<5 \%$ by morphology with blood count recovery. ${ }^{\ddagger} \mathrm{MRD}$ by cytogenetics. ${ }^{5}$ Patient had a DQ allele mismatch unrelated donor. "Patient had an HLA-A antigen mismatch unrelated donor. 


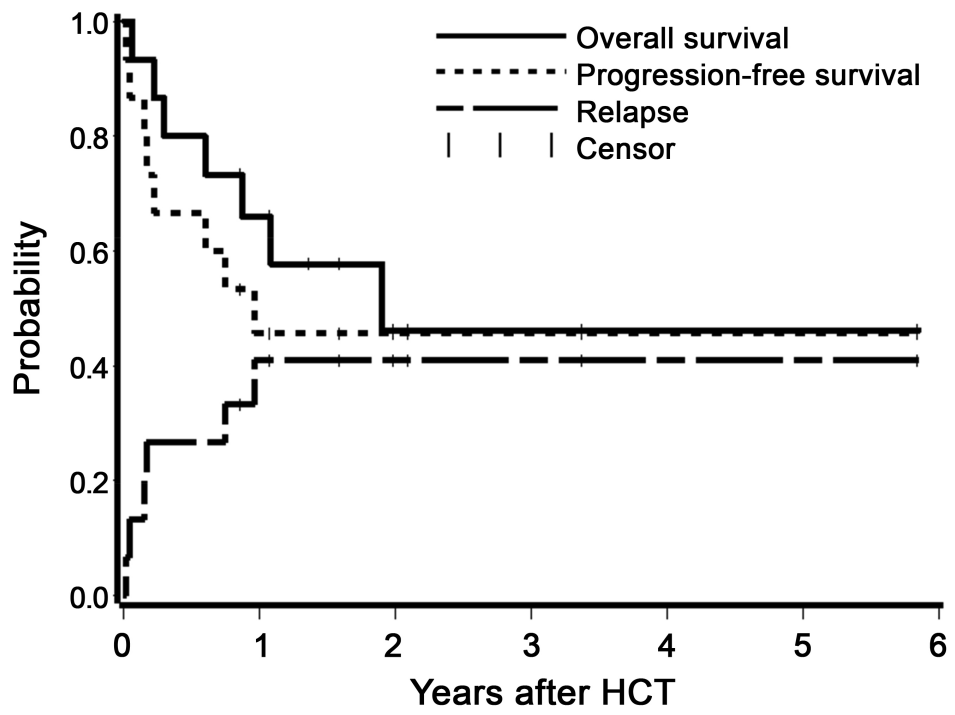

Figure 2. Estimates of the probability of overall survival, relapse-free survival, and relapse among all patients who received a therapeutic dose of ${ }^{90} \mathrm{Y}$-DOTA-BC8 followed by total body irradiation/fludarabine. HCT: allogeneic hematopoietic cell transplantation.

outcomes even with myeloablative HCT, with 3-year estimates of relapse of $65 \%{ }^{3,36}$ Our study establishes proof of principle that radioimmunoconjugates can deliver supplemental doses of radiation to sites of leukemic involvement and have the potential to improve the cure rate by decreasing the risk of relapse in these high-risk patients.

More importantly, the results presented here show the feasibility of using ${ }^{90}$ Y-DOTA-BC8 combined with reduced-intensity allogeneic HCT for patients with highrisk MDS and AML. Engraftment was not delayed after delivery of ${ }^{90}$ Y-DOTA-BC8, and infusion-related toxicities were mild and manageable. Intensified conditioning with ${ }^{90}$ Y-DOTA-BC8 resulted in few toxicities beyond those expected with FLU and TBI alone with no grade 4 adverse events reported. Most commonly seen grade 3 adverse events were neutropenic fever with or without identified sources of infection and constitutional symptoms. There was one case of NRM in the first 100 days after transplantation that was not attributed to the investigational therapy among the 15 patients treated. Taken altogether, these findings suggest that this transplantation-conditioning strategy has acceptable toxicity profiles while complementing the efficacy of reduced-intensity conditioning, and demonstrates the potential exportability of this approach to other patient populations with hematologic malignancies.

The overall incidence of grades II to IV acute GvHD in this study was $67 \%$. This incidence is similar to that seen with FLU or TBI alone at our center. ${ }^{17}$ The incidence of chronic GvHD (33\%) in the current study is comparable to that among patients who received reduced intensity conditioning without targeted radiotherapy, suggesting that the radiolabeled antibody has no demonstrative effect on the risk of chronic GvHD. ${ }^{18,19}$

Although we previously estimated an MTD of 24 Gy in our study using ${ }^{131} \mathrm{I}-\mathrm{BC} 8,{ }^{2}$ no grade III or IV DLT were observed when the same antibody was conjugated to ${ }^{90} \mathrm{Y}$, despite targeted doses of up to 30 Gy to the liver (median dose 19 Gy), suggesting that higher doses of radiation may be tolerated in the marrow or spleen. Nonetheless, theoretical concerns persist about both the short- and long-term consequences of ${ }^{90} \mathrm{Y}$ at higher doses due to its long path- length. After treating these 15 patients, grant funding was exhausted, and in seeking renewed funding, we chose instead to pursue $\alpha$ emitters for two reasons. First, given the lack of DLT even after reaching 30 Gy to liver, it seemed unlikely that we would be able to load enough ${ }^{90} \mathrm{Y}$ onto the amount of antibody that provides optimal biodistribution without damaging the antibody itself. ${ }^{20}$ Secondly, $\alpha$-emitting radionuclides have a higher linear energy transfer that is coupled with a short path length capable of killing the target cells with only a few cell traversals, thereby potentially providing even greater specificity at high radiation doses. ${ }^{21}$ Ongoing studies are evaluating the use of an $\alpha$ emitter, astatine-211, conjugated to anti-CD45 antibody BC8 as part of an HCT conditioning regimen for patients with advanced leukemia or high-risk MDS.

In summary, the delivery of supplemental radiation to bone marrow and spleen by ${ }^{90}$ Y-DOTA-BC8 was well tolerated when combined with FLU/TBI in patients undergoing HCT for advanced AML and high-risk MDS who were not candidates for myeloablative HCT. The encouraging results from this study support more clinical trials using radioimmunotherapy as part of the conditioning regimen for allo-HCT. The antileukemic potential of this approach, combined with the promise of reduced toxicity, may improve outcomes after allogeneic HCT for patients with advanced hematologic malignancies.

\section{Acknowledgments}

The authors thank the patients who participated in the clinical trial. They also thank their colleagues in the transplant services, the research staff, and clinical staff. We greatly appreciate Monina Almeda's assistance in data management and regulatory support, and Helen Crawford's assistance with manuscript preparation.

\section{Funding}

Research funding was provided by the National Institutes of Health, Bethesda, MD, grants, P01 CA044991, P01 CA078902, and P30 CA015704 from the National Cancer Institute. The content is solely the responsibility of the authors and does not necessarily represent the official views of the National Institutes of Health nor its subsidiary Institutes and Centers. 


\section{References}

1. Kahl C, Storer BE, Sandmaier BM, et al. Relapse risk among patients with malignant diseases given allogeneic hematopoietic cell transplantation after nonmyeloablative conditioning. Blood. 2007;110(7):2744-2748.

2. Pagel JM, Gooley TA, Rajendran J, et al. Allogeneic hematopoietic cell transplantation after conditioning with 131I-antiCD45 antibody plus fludarabine and lowdose total body irradiation for elderly patients with advanced acute myeloid leukemia or high-risk myelodysplastic syndrome. Blood. 2009;114(27):5444-5453.

3. Araki D, Wood BL, Othus $M$, et al. Allogeneic hematopoietic cell transplantation for acute myeloid leukemia: Time to move toward a minimal residual diseasebased definition of complete remission? J Clin Oncol. 2016;34(4):329-336.

4. O'Donoghue JA. Optimal therapeutic strategies for radioimmunotherapy. Recent Results Cancer Res. 1996;141:77-99.

5. McSweeney PA, Niederwieser D, Shizuru JA, et al. Hematopoietic cell transplantation in older patients with hematologic malignancies: replacing high-dose cytotoxic therapy with graft-versus-tumor effects. Blood. 2001;97(11):3390-3400.

6. Bearman SI, Appelbaum FR, Buckner CD, et al. Regimen-related toxicity in patients undergoing bone marrow transplantation. J Clin Oncol. 1988;6(10):1562-1568.

7. Storer BE. Small-sample confidence sets for the MTD in a phase I clinical trial. Biometrics. 1993;49(4):1117-1125.

8. Slovak ML, Kopecky KJ, Cassileth PA, et al. Karyotypic analysis predicts outcome of preremission and postremission therapy in adult acute myeloid leukemia: a Southwest Oncology Group/Eastern Cooperative Oncology Group study. Blood. 2000;96(13):4075-4083.

9. Sierra J, Storer B, Hansen JA, et al. Transplantation of marrow cells from unrelated donors for treatment of high-risk acute leukemia: the effect of leukemic burden, donor HLA-matching, and marrow cell dose. Blood. 1997;89(11):4226-4235.

10. Miller CB, Zehnbauer BA, Piantadosi S, Rowley SD, Jones RJ. Correlation of occult clonogenic leukemia drug sensitivity with relapse after autologous bone marrow transplantation. Blood. 1991;78(4):11251131.

11. Clift RA, Buckner CD, Appelbaum FR, et al. Allogeneic marrow transplantation in patients with acute myeloid leukemia in first remission: A randomized trial of two irradiation regimens. Blood. 1990;76(9):1867-1871.

12. Laport GG, Sandmaier BM, Storer BE, et al Reduced-intensity conditioning followed by allogeneic hematopoietic cell transplantation for adult patients with myelodysplastic syndrome and myeloproliferative disorders. Biol Blood Marrow Transplant. 2008;14(2):246-255

13. Sorror ML, Storer BE, Sandmaier BM, et al Five-year follow-up of patients with advanced chronic lymphocytic leukemia treated with allogeneic hematopoietic cell transplantation after nonmyeloablative conditioning. I Clin Oncol 2008;26(30):4912-4920.

14. Gyurkocza B, Storb R, Storer BE, et al. Nonmyeloablative allogeneic hematopoietic cell transplantation in patients with acute myeloid leukemia. J Clin Oncol
2010;28(17):2859-2867.

15. Mawad R, Gooley TA, Rajendran JG, et al Radiolabeled anti-CD45 antibody with reduced-intensity conditioning and allogeneic transplantation for younger patients with advanced acute myeloid leukemia or myelodysplastic syndrome. Biol Blood Marrow Transplant. 2014;20(9):1363-1368.

16. Walter RB, Gyurkocza B, Storer BE, et al. Comparison of minimal residual disease as outcome predictor for AML patients in first complete remission undergoing myeloablative or nonmyeloablative allogeneic hematopoietic cell transplantation. Leukemia. 2015;29(1):137-144.

17. Mielcarek M, Burroughs L, Leisenring W, et al. Prognostic relevance of early-onset graft-versus-host disease following nonmyeloablative hematopoietic cell transplantation. Br J Haematol. 2005;129(3):381 391.

18. Wong R, Giralt SA, Martin T, et al. Reduced-intensity conditioning for unrelated donor hematopoietic stem cell transplantation as treatment for myeloid malignancies in patients older than 55 years. Blood. 2003;102(8):3052-3059.

19. Kroger N, Bornhauser M, Ehninger G, et al Allogeneic stem cell transplantation after a fludarabine/busulfan-based reduced-intensity conditioning in patients with myelodysplastic syndrome or secondary acute myeloid leukemia. Ann Hematol. 2003;82(6):336-342.

20. Salako OA, O'Donnell RT, DeNardo SJ Effects of radiolysis on yttrium-90-labeled Lym-1 antibody preparations. J Nucl Med. 1998;39(4):667-670

21. Hall EJ, Giaccia AJ. Radiobiology for the radiologist. 6th ed. Philadelphia: Lippincott Williams \& Wilkins, 2006. 